\title{
Friedrich Schiller e Gonçalves Dias
}

Karin Volobuef*

\begin{abstract}
In this essay I want to begin with a short survey on the reception of Schiller in England and Portugal, especially in regard to the impact of the play The Robbers and the narrative The Ghostseer. As a matter of fact, Schiller was not only read and translated, but he actually imprinted his mark on (the) literature outside Germany. His ideas and works made important contributions to the Romantic movement - that of Brazil, where his writings arrived through France and Portugal, but Schiller was read directly in German at least by Gonçalves Dias. Schiller's contribution to the works of Gonçalves Dias can be most clearly seen in the drama Patkull, in which there are similarities to Wallenstein, and in the translation of The bride of Messina, which was unfinished when the Brazilian writer prematurely died.
\end{abstract}

Keywords: Friedrich Schiller; Wallenstein; Gonçalves Dias; Patkull

Zusammenfassung: In diesem Essay möchte ich anfangs einige Informationen über Schillers Rezeption in England und Portugal zusammenbringen, hauptsächlich was die Wirkung des Stückes Die Räuber und der Erzählung Der Geisterseher betrifft. Schiller wurde dort nämlich nicht nur gelesen und übersetzt, sondern hat auch tiefe Spuren in der Literatur dieser Länder hinterlas-

A autora é professora doutora do Departamento de Letras Modernas, Área de Língua e Literatura Alemã, UNESP. Rodovia Araraquara-Jaú, km 1 - CEP 14800901 Araraquara SP - e-mail: volobuef@fclar.unesp.br. 
sen. Mit seinen Ideen und Werken gab er einen äußerst wichtigen Anstoß für die Romantiker vieler Länder - auch in Brasilien. Als Vermittler fungierten dabei Frankreich und Portugal, doch zumindest von Gonçalves Dias wurde Schiller direkt auf Deutsch gelesen. Die Bedeutung Schillers für das Schaffen von Gonçalves Dias kommt besonders deutlich zum Ausdruck in dem Drama Patkull, das sich an den Wallenstein anlehnt. Schillers Bedeutung wird aber auch sichtbar bei der Übertragung der Braut von Messina ins Portugiesische, an welcher der brasilianische Romantiker noch emsig arbeitete, als er frühzeitig aus dem Leben schied.

Stichwörter: Friedrich Schiller; Wallenstein; Gonçalves Dias; Patkull

Resumo: O artigo retraça algumas etapas da recepção de Schiller na Inglaterra e Portugal, especialmente no que se refere ao impacto causado pela peça $O s$ bandoleiros e a narrativa $O$ visionário. Schiller não apenas foi lido e traduzido, mas suas obras efetivamente produziram ecos na literatura fora da Alemanha. Seu estímulo, idéias e criações sem dúvida deram um impulso fundamental para o Romantismo de muitos países - inclusive do Brasil. Aqui suas reverberações chegaram via França ou Portugal, mas, pelo menos no caso de Gonçalves Dias, Schiller foi lido diretamente em alemão. A importância de Schiller para a obra de Gonçalves Dias pode ser percebida com maior clareza na peça Patkull, que se ampara em Wallenstein, e também na tradução $A$ noiva de Messina, em que o romântico brasileiro trabalhava na época de sua morte tão precoce.

Palavras-chave: Friedrich Schiller; Wallenstein; Gonçalves Dias; Patkull

\section{Friedrich Schiller}

A produção de Friedrich Schiller cobre um leque imenso de formas e temas. Schiller pode ser lido e discutido sob o ponto de vista da poesia e do teatro, mas também da história, da filosofia, da política, etc. Seu nome aparece em estudos sobre a balada, em investigações sobre a Revolução Francesa, em trabalhos sobre o mito. Para os alemães, foi um clássico; para o resto da Europa, um romântico. Conservador para uns, revolucionário para outros. De um lado, o dramaturgo que reintroduziu o coro no teatro em pleno século XIX, de outro, o pensador arrojado que em seu ensaio Poesia 
ingênua e sentimental discutiu a oposição entre a Natureza e o Belo e, com isso, trouxe à baila duas noções que serão fundamentais para a teoria romântica. Leitor assíduo de Rousseau e, notoriamente, de Kant - Schiller foi um pensador irrequieto e ousado, que não teve medo de desafiar os poderosos ou de entrar em choque com as normas estabelecidas. Pobre e sem padrinhos influentes, ao longo de seus 46 anos de idade manteve-se fiel a seus ideais em defesa da liberdade do indivíduo e em prol de um senso estético apurado. De um lado, enalteceu os deuses da Grécia; de outro, criou o personagem Karl Moor, um fora-da-lei charmoso e emblemático que assaltava os ricos e acolhia os pobres.

Com essa abrangência, Schiller produziu um conjunto de obras que representa um monumento cultural não apenas no cenário da Alemanha, mas de várias nações, inclusive o Brasil, conforme veremos mais adiante em relação a Gonçalves Dias. E essa presença tão marcante ocorreu já desde a primeira peça de Schiller - Die Räuber ou Os bandoleiros, de 1781. Ao lado de outras obras, como o Werther de Goethe, ou a balada Lenore, de Gottfried A. Bürger, Os bandoleiros deixou uma marca tão forte, que não se poderia imaginar o Romantismo de vários países sem ela. No caso de Os bandoleiros, principalmente a vertente do Romantismo social - representada por Victor Hugo na França, Castro Alves no Brasil - não seria a mesma se não tivesse recebido, direta ou indiretamente, o estímulo proveniente de Schiller.

É o que vemos, por exemplo, em Portugal. Alexandre Herculano inspirou-se n'Os bandoleiros, ao compor seu poema $A$ semana santa (escrito em 1829). Apesar do título, que parece indicar uma temática religiosa, o poema volta-se contra o absolutismo e contra o domínio dos ingleses em solo português, e manifesta-se em prol das liberdades civis. Para Antônio Serpa (Herculano 1959: XIX), o poema $A$ semana santa é um verdadeiro "manifesto liberal", ou seja, uma defesa da burguesia portuguesa, classe até então subjugada pela aristocracia e pelo domínio inglês. Para servir de epígrafe a seu poema, Alexandre Herculano escolheu uma frase do ato 5 (cena 1) d'Os bandoleiros: "O pensamento chamado Deus desperta um vizinho temível cujo nome é Juiz:" (SCHILLER 2001: 209, grifo no original). Na peça de Schiller essa frase é dita pelo pastor Moser, que procura sensibilizar o tirano Franz Moor (irmão do bandido simpático Karl Moor) e fazer com que ele se 
arrependa dos seus abusos e crueldades. No poema de Alexandre Herculano, Deus é invocado para sensibilizar o partido absolutista liderado por D. Carlota Joaquina e o infante D. Miguel, derrotados por D. Pedro IV (D. Pedro I no Brasil), o qual liderou a causa liberal e levou D. Maria II ao trono em 1834. Para Antônio Serpa o poema é representativo do pensamento político de Alexandre Herculano, e versos como "Creio que Deus é Deus e os homens livres!” (Herculano 1959: 7) estariam imbuídos do mesmo espírito de defesa incondicional da liberdade que Schiller imprimiu em sua peça Os bandoleiros.

$\mathrm{Na}$ Inglaterra, a tradução da peça de Schiller - The Robbers, feita por A. F. Tytler - apareceu em 1792 (PIRIE 1994: 499). Na terra de Robin Hood, o impacto de Karl Moor foi enorme. E não apenas pelo seu papel de nobre bandido. O público inglês percebeu no protagonista schilleriano uma angústia semelhante à de Hamlet (o que se expressa, p.ex., no monólogo de Moor no Ato 4, cena 5). Além disso, Karl tem um caráter duplo - de anjo e de demônio -, que o aproxima do Lúcifer em Paradise Lost, de John Milton. Longe de ser uma figura simples, Karl Moor fascinou pelas suas contradições. Como resultado, na visão de alguns críticos (FAIRCHILD 1931: 36), é dele que vêm os principais ingredientes que um pouco mais tarde vão compor o herói byroniano: um jovem descrente e atormentado, impulsivo e desafiador, um misto de filósofo e marginal.

Samuel Coleridge, um dos fundadores do movimento romântico inglês, ficou extremamente impressionado com a obra e, em 1798, viajou com Wordsworth para a Alemanha, passando depois a dedicar-se intensamente à leitura da filosofia e literatura alemãs (Furst 1979: 39). Dessa atividade resultou, por fim, sua tradução do Wallenstein em 1800 (PIRIE 1994: 211; FAIRCHILD 1931: 261).

Um ano antes, em 1799, Scott havia publicado sua tradução da peça Götz von Berlichingen, de Goethe, ambientada no séc. XVI (aprox. 1525). ${ }^{1}$ Esse interesse por Götz e Wallenstein nos primórdios do séc. XIX evidencia a preocupação dos ingleses pela temática histórica. Pouco depois, em 1814, Walter Scott cria o romance histórico, ou seja, transpõe para a narrativa o que

1 Götz von Berlichingen viveu de 1480 a 1562. 
Schiller e Goethe faziam no teatro. Talvez os dois alemães tenham contribuído mais do que se imagina para o surgimento desse novo gênero literário.

De qualquer modo, a forte presença do medievalismo no final do século XVIII e início do XIX marcou a obra de muitos românticos. No caso de Byron, ele se mescla principalmente com elementos macabros e góticos. Em uma carta de 11.08.1807, endereçada a Miss Pigot (FAIRCHILD 1931: 302-303), Byron afirma que uma de suas fontes foi a narrativa Der Geisterseher ou O visionário (1788), de Schiller. Nesse texto, Schiller reuniu elementos que tinham um enorme apelo para o leitor de seu tempo: sociedades secretas, magia e ocultismo, intrigas de jesuítas e charlatães. Mesmo assim, nem o próprio Schiller imaginava um sucesso tamanho. $\mathrm{Na}$ verdade, foi tão grande que ultrapassou as fronteiras geográficas e lingüísticas e chegou até a Inglaterra.

$E$ isso porque havia então entre os ingleses um grande interesse pela literatura alemã. Como resultado, em 1795 Timaeus publicou The Ghostseer, a primeira tradução inglesa da narrativa Der Geisterseher. No entender de alguns críticos, a narrativa schilleriana foi uma das fontes para o romance gótico The Monk (1796) de Matthew Gregory Lewis. Lewis, aliás, ainda tem seu nome ligado ao de Schiller em outro momento áureo de sua carreira: em 1797, conquistou a fama de exímio tradutor com sua versão The Minister da peça Kabale und Liebe (ou Intriga e amor).

Em Portugal, a narrativa Der Geisterseher, de Schiller, foi traduzida por Alexandre Herculano. Sua leitura também foi estimulante para os portugueses. Dela veio a inspiração para o poema $A$ noite do castelo (publ. em 1836), de Antônio Feliciano de Castilho (FrançA 1993: 205). Grande fomentador da literatura gótica portuguesa, tradutor do Fausto de Goethe, Castilho foi também uma figura importante para a carreira literária de Gonçalves Dias.

E com Gonçalves Dias Schiller vai chegar ao Brasil.

É bem verdade que Gonçalves Dias é conhecido nas letras brasileiras como o grande poeta indianista e, para Antonio Candido (1981: 81), ele é “o verdadeiro criador da literatura nacional" - e não Gonçalves de Magalhães, o dito introdutor oficial do Romantismo brasileiro. Autor das Poesias americanas (1846), de I Juca Pirama (1857) e Os timbiras (1857), Gonçalves 
Dias foi saudado por Machado de Assis no Brasil, por Alexandre Herculano em Portugal. Sua obra, porém, não se restringe ao indianismo. Menos conhecida, é na sua obra teatral que encontraremos alguns dos rastros de Schiller no Brasil.

\section{Schiller no Brasil: Gonçalves Dias}

Gonçalves Dias nasceu no Maranhão em 1823, indo mais tarde estudar Direito em Coimbra, onde permaneceu de 1838 a 1844. Em 1845, aos 21 anos de idade, embarcou de volta ao Brasil. Não tinha dinheiro algum, nem mesmo para a passagem, que teve que ser paga pela madrasta, no Maranhão. Em sua bagagem trazia, porém, sua verdadeira riqueza, ou seja, os frutos literários de sua estadia em Coimbra: a famosa "Canção do exílio", as peças teatrais Patkulle Beatriz, Cenci, e o romance autobiográfico Memórias de Agapito Goiaba.

Além disso, a presença em Coimbra também fez com que estudasse a fundo os clássicos portugueses, colaborasse na redação do periódico $O$ trovador, e aderisse ao grupo de medievalistas ativo na cidade (FIQUEIREDO 1966: 348; MoIsÉs 1971: 165-166; BANDEIRA 1962: 17). Esse entrosamento com a tradição literária portuguesa e com os românticos lusitanos despertou o entusiasmo de Antônio Feliciano de Castilho, que se prontificou ${ }^{2}$ a publicar o poema "O índio" na Revista universal lisboense (CANDIDO 1981: 8283; BANDEIRA 1962: 27).

Além de tudo isso, foi durante a estadia em Coimbra (em 1843) que Gonçalves Dias iniciou os estudos da língua alemã, tornando-se o único romântico brasileiro a dominar esse idioma e a poder ler diretamente no original. Como resultado dessa fluência podemos encontrar na obra de Gonçalves Dias diversas marcas que apontam para a amplitude de suas leituras. É bem verdade que outros românticos brasileiros, como Álvares de Azevedo e Visconde de Taunay, também demonstram conhecer Klopstock, Schiller, Goethe, Hoffmann. Gonçalves Dias, porém, chega a citá-los diretamente em língua alemã. A famosa "Canção do exílio" (DiAs

2 Uma oferta que não chegou a ser aceita, pois Gonçalves Dias preferiu guardar o poema para publicação no Brasil. 
1949: 350), por exemplo, traz como epígrafe os versos iniciais da canção de Mignon "Kennst du das Land, wo die Zitronen blühen" do romance Wilhelm Meister, de Goethe. Fora ela, outros poemas ainda são antecedidos por trechos de Schiller, Kleist, Wieland.

Mas a ligação de Gonçalves Dias com a Alemanha não ficou apenas no papel. Em 1852 Gonçalves Dias foi nomeado oficial da Secretaria dos Negócios Estrangeiros, partindo dois anos mais tarde para a Europa. Em 1856 chegou à Alemanha, onde, um ano depois, a editora Brockhaus de Leipzig publicou sua antologia Cantos, a parte inicial (cantos I a IV) do poema Os Timbiras e o Dicionário de Tupi (Menezes 1978: 233).

Conforme já apontaram vários estudiosos, as poesias gonçalvianas deixam entrever o reflexo das obras de autores como Victor Hugo, Gautier, Dante, Herculano, Garrett, Basilio da Gama (CANDIDO 1981: 88-89; RICARDO 1986: 115-119). Já as peças teatrais, a começar pelas escritas em Coimbra, revelam o diálogo com Friedrich Schiller - diálogo esse atestado pela temática histórica, a linguagem elevada e a estrutura construída segundo padrões clássicos.

A produção dramática de Gonçalves Dias compreende as seguintes peças: Patkull (1843), Beatriz Cenci (1843), Leonor de Mendonça (1847) e Boabdil (1850). Nesses textos, visita respectivamente a Alemanha de 1707, a Itália de 1598, Portugal de 1512, a Espanha dos tempos da presença árabe (1492), e aborda temas como traição, pena de morte, incesto, adultério, que sem dúvida dificultaram o acesso não apenas aos palcos brasileiros, como também à chance de publicação.

Como resultado, Boabdil foi traduzida e encenada na Alemanha, não no Brasil. Beatriz Cenci foi rejeitada pelo Conservatório Dramático (órgão com poderes de censura) sob a alegação de que era imoral, ou conforme outras interpretações, porque a linguagem empregada não era correta (RiCARDO 1986: 120-121; JACOBBI 1958: 41). Essa objeção, aliás, teria levado Gonçalves Dias a escrever Sextilhas de Frei Antão em português arcaico a fim de demonstrar seus conhecimentos do idioma. Leonor de Mendonça, que Décio de Almeida Prado (1993: 247) chama de "O mais belo drama do nosso romantismo - e talvez de todo o teatro brasileiro", foi aceita pelo Conservatório, mas João Caetano recusou-se a atuar nela (JACOBBI 1958: 62-63). Por fim, Leonor de Mendonça foi encenada no Maranhão, tornando-se 
inclusive a única obra teatral de Gonçalves Dias a ser publicada ainda em vida do poeta (a impressão se deu em 1847). As demais peças permaneceram inéditas até saírem na edição de Obras póstumas em 1868-1869 (MAGALDI s.d.: 67; RiCARDO 1986: 70).

No que se refere a Patkull - a peça ambientada na Alemanha de 1707 - talvez a sua fonte de inspiração também seja uma obra alemã. Não se sabe ao certo se Gonçalves Dias conhecia o romance Patkul - Historischer Roman (1835), que Nina Rog publicou em Leipzig pela editora Kollmann. Entretanto, os comentadores apontam para duas obras como sendo as principais fontes que o autor teria consultado. Uma delas é a História de Carlos XII (1731), de Voltaire, de onde Gonçalves Dias teria extraído os eventos da vida do protagonista Patkul e, inclusive, a equivocada grafia "Patkull". A segunda seria a peça histórica Wallenstein ${ }^{3}$ (1799), de Friedrich Schiller, que teria fornecido não apenas informações gerais sobre a Guerra dos Trinta Anos (1618-1648), como também a inspiração estética (JACOBBI 1958: 49, 51).

A ação de Patkull desenrola-se principalmente na Alemanha (em Mecklenburg e Dresden), enquanto o desfecho se passa na Polônia (em Casemir, nas imediações de Posen). O protagonista da peça é uma figura histórica: Johann Reinhold Patkul (1660-1707), um gentil-homem sueco, que prestou serviços a Augusto II da Saxônia e Polônia e ao czar russo Pedro I. Por fim, em 1707, foi executado na roda, segundo as ordens de Carlos XII, rei da Suécia.

O personagem central de Patkull é um herói sensível e apaixonado, que se torna alvo de inveja e traições. Gonçalves Dias busca no contexto histórico apenas os elementos necessários para caracterizar seu protagonista como homem valoroso na batalha e, uma vez conseguida essa caracterização, o olhar passa a afastar-se do plano histórico para fixar-se nos conflitos emocionais e existenciais.

Ao contrário de Schiller - que mostrou Wallenstein como guerreiro heróico mas também como figura orgulhosa e dilacerada por impulsos demoníacos - Gonçalves Dias cria um Patkull absolutamente íntegro, fiel,

3 Peça da qual não há tradução brasileira, a despeito de ter atraído ampla divulgação: foi traduzida para o francês por Benjamin Constant e para o inglês por Coleridge. 
valoroso até o momento de sua execução. A peça acompanha o período final de sua vida, ou seja, a época em que, desiludido em seus ideais de libertar a pátria, é vítima da traição de Paikel, a quem julgava um amigo.

Entretanto, justamente essas circunstâncias nos fazem voltar novamente a Schiller, que seguiu um plano dramático muito semelhante em Don Carlos (1787). Nesta peça, intrigas palacianas, promessas de ações militares, interesses da Igreja e da Coroa preparam o desfecho trágico, em que o príncipe Carlos é traído pelo seu próprio pai, Filipe II da Espanha, e entregue aos algozes da Inquisição. O conflito entre as paixões e o dever é, portanto, o núcleo das peças de Schiller e de Gonçalves Dias.

Por detrás da trama de Patkull sobressai uma concepção trágica típica de Schiller: não é o destino supra-individual - coordenado pelas Parcas, tecelãs do fio da vida - que dá as cartas e determina a sorte ou o azar. Pelo contrário, são as condições históricas e políticas da época, e a própria constituição psicológica, social e moral do personagem, que dirigem as decisões do herói e conduzem seus passos.

Isso fica claro, por exemplo, na peça Maria Stuart (1800), cuja protagonista toma a decisão de humilhar-se perante a rainha Elizabeth I a fim de conseguir salvar-se. Contudo, uma vez confrontada com sua rival, sua natureza mais profunda - altiva e orgulhosa de sua realeza - fala mais alto, fazendo com que ela prefira perder a vida mas mantenha intacta a dignidade. Da mesma forma, os valores íntimos de Patkull fazem dele uma presa fácil. O falso amigo Paikel apenas consegue envolver Patkull em seu plano traiçoeiro porque o herói coloca acima de tudo seu sentimento de patriotismo e sua fidelidade ao povo. Além disso, Patkull confia tão cegamente no amor e na amizade que não consegue ter qualquer desconfiança em relação a Paikel. Esses valores humanistas de Patkull constituem mais um aspecto absorvido de Schiller.

Para conferir isso, precisamos antes lembrar que Schiller foi catedrático de História em Jena, tendo redigido vários ensaios sobre a Guerra dos Trinta Anos, as cruzadas, a independência dos Países Baixos, etc. Gonçalves Dias, por sua vez, também escreveu um texto de cunho historiográfico - Reflexões sobre os Anais historicos do Maranbão por Berredo (PARAnHos 1937: 86 e 102). Nesse texto, o nome de Schiller está emparelhado com o de Chateaubriand, Homero e Platão enquanto "historiador poeta". Para Gon- 
çalves Dias, o "historiador poeta resume as nações em uma só nação, simpatiza com todas as suas grandezas, execra todas as suas torpitudes, e generalizando todos os sentimentos, todas as aspirações do coração humano, tem por fim - a humanidade." (Montello 1973: 129-130). Ao escrever uma peça sobre Patkull, figura que parece absolutamente desconecta da realidade histórica e cultural do Brasil, Gonçalves Dias coloca em prática esse mesmo senso de humanidade que ele vislumbrou e admirou em Schiller.

Depois de tudo isso, o que coroou a admiração de Gonçalves Dias por Schiller foi seu projeto de traduzir Die Braut von Messina, ou A noiva de Messina, de Schiller. De acordo com os biógrafos, é provável que a tradução tenha sido iniciada em 1859, ainda durante sua estadia na Alemanha. Raimundo de MENEZES (1978: 233) acredita que ela tenha sido concluída em 1863, em Lisboa. Gonçalves Dias trazia consigo a versão final do trabalho ao embarcar em 1864 no navio Ville de Boulogne para retornar ao Brasil. Quando a embarcação francesa chegou próximo da baía de Cumã no Maranhão, chocou-se com recifes e naufragou. Gonçalves Dias não conseguiu salvar-se. Segundo o depoimento do capitão do navio, publicado pelo jornal Commercio do Paraná em dezembro de 1864, Gonçalves Dias morreu ao ser atingido pelo mastro da embarcação, que desabou sobre seu camarote. Segundo informações de Haroldo PARANHOS (1937: 84), o Jornal do Pará e o Jornal do Recife também noticiaram a entrevista, mas repetindo as informações apresentadas pelo Commercio do Paraná.

Nesse desastre faleceu um dos maiores poetas brasileiros - e também foi perdida a versão final e revisada da tradução $A$ noiva de Messina. O que restou foi um manuscrito contendo a versão ainda inacabada.

\section{Schiller nos dias de hoje}

A editora Cosac \& Naify publicou nova edição d' $A$ noiva de Messina em 2004. Ou seja, 140 anos após a morte de Gonçalves Dias e um ano antes do bicentenário da morte de Friedrich Schiller. Em 2005, a Editora da UFPR lançou Intriga e amor. Cabe perguntar agora como nós, em pleno século XXI, podemos ler e entender Schiller.

Já Thomas Mann em seu discurso de 1955 - ou seja, na comemoração dos 150 anos da morte de Schiller - perguntava-se a mesma coisa. Também Thomas Mann questionava a possibilidade de os valores clássicos 
de Schiller serem compreensíveis e aceitáveis aos seus contemporâneos. Para Mann, a primeira metade do séc. XX foi uma época de perda da cultura e das noções de respeito, fé, justiça e integridade. Ou seja, de todos os valores que formam a base das idéias schillerianas de universalidade, beleza e perfeição. Ao invés de aspirar a ir além, de ultrapassar seus próprios limites, o homem moderno seria alguém resignado, cansado, perdido. Depois das armas químicas da Primeira Guerra, depois das câmaras de gás e bombas atômicas da Segunda, a própria palavra "humanidade", tão preciosa para Schiller, também parece ter perdido muito de seu significado.

Da época de Mann até agora, isto é, nesses últimos 50 anos, será que a situação mudou? Será que as perdas diagnosticadas naquele discurso foram compensadas? Ou será que, ao contrário, o homem pós-moderno encontra-se ainda mais desnorteado do que no século passado?

Antes de mais nada, é preciso considerar que o nome de Schiller foi bastante "usado" e desfigurado. Se em 1933 seu personagem Wilhelm Tell foi festejado como símbolo da identidade nacional, em 1941 o mesmo Wilhelm Tell foi proibido pela censura devido a seu caráter subversivo. Talvez Wilhelm Tell não seja nem uma coisa, nem outra. Ou então, talvez seja as duas. E isto porque Schiller talvez não seja tão essencialmente clássico como muitas vezes se acredita. Seu objetivo pode não ter sido uma universalidade e perfeição padronizadas e gastas.

Ao contrário disso, a leitura de Schiller hoje pode nos revelar um pensador que defendia a autodeterminação do homem e o direito de cada um de escolher o seu próprio caminho. Schiller acreditava no potencial de cada indivíduo. Ele também presenciou grandes conflitos bélicos e carnificinas. A Revolução Francesa, a guilhotina trabalhando sem parar durante o período do Terror (1793-4) e as guerras napoleônicas foram episódios sangrentos que desestabilizaram as certezas e instalaram o sentimento de crise. Por isso, Schiller não é o representante do equilíbrio sereno, mas alguém em busca de um novo significado. Quando todos os sentidos estão perdidos e aquilo que parecia eterno é extinto - como é o caso na nossa época e na dele - Schiller se empenhou em procurar alternativas para suplantar o vazio. Como analisou K. K. Ruthven no seu livro $O$ mito, "Friedrich Schiller foi um dos primeiros a testificarem [a] nostalgia [por] uma mitologia perdida que as artes devem recuperar para poder sobreviver." (1997: 80). 
Essa busca pelo mito, pela essência, pelo sentido mais profundo e mais humano é o que Schiller pode oferecer.

\section{Referências bibliográficas}

ACKermann, Fritz. A obra poética de Gonçalves Dias. Tradução de Egon Schaden.

São Paulo, Conselho Estadual de Cultura 1964. (Coleção Ensaio, 32).

BAndeira, Manuel. Poesia e vida de Gonçalves Dias. São Paulo, Ed. das Américas 1962.

CANDIDO, Antonio. Formação da literatura brasileira: Momentos decisivos. v. 2.

6. ed. Belo Horizonte, Itatiaia 1981.

Dias, Antônio Gonçalves. Obras. In: ramos, Frederico José da Silva (Organização, revisão e notas). Grandes poetas românticos do Brasil: Poesias completas. Prefácio e notas biográficas de Antônio Soares Amora. São Paulo, Lep 1949, 347-556.

- Teatro completo. Rio de Janeiro, Serviço Nacional de Teatro 1979.

(Coleção Clássicos do Teatro Brasileiro, 2)

FAIrCHILD, Hoxie Neale. The Romantic Quest. New York, Columbia University Press 1931.

FRANÇA, José-Augusto. O romantismo em Portugal. Estudo de factos socioculturais.

Trad. Francisco Bronze. 2. ed. Lisboa, Livros Horizonte 1993.

Fransbach, Martin. Gonçalves Dias 'Canção do exílio' und Goethes 'Mignon' - Interpretation und Quellenvergleich. Revista de Letras. Assis (UNESP), v. 6, 1965, 119-128.

FURST, Lilian R. Romanticism in Perspective. A Comparative Study of Aspects of the Romantic Movements in England, France and Germany. 2. ed. London, Macmillan Press 1979.

Goethe, Wolfgang. Fausto; Poema dramático. Trad. António Feliciano de Castilho. 3. ed. São Paulo, Livraria Teixeira s.d. Os anos de aprendizado de Wilhelm Meister. Tradução Nicolino Simone Neto. São Paulo, Ensaio 1994. 
. Raineke-Raposo. São Paulo, Companhia das Letras 1998.

Herculano, Alexandre. Obras. 2 v. São Paulo, Saraiva 1959.

JacobBi, Ruggero. Goethe, Schiller, Gonçalves Dias. Porto Alegre, Universidade do Rio Grande do Sul 1958. (Série Letras, 5)

MAgaldi, Sábato. Panorama do teatro brasileiro. S/1, Serviço Nacional de Teatro s/d. (Coleção Ensaios, 4)

MENEZES, Raimundo de. Dicionário literário brasileiro. 2. ed. rev. aum. e atual.

Rio de Janeiro, Livros Técnicos e Científicos 1978.

MoIsÉs, Massaud. A literatura portuguesa. 9. ed. São Paulo, Cultrix 1971.

MONTELLO, Josué. Para conhecer melhor Gonçalves Dias. Rio de Janeiro, Bloch Editores 1973.

PARANHos, Haroldo. História do romantismo no Brasil. v. 2. São Paulo, Edições Cultura Brasileira 1937. (1830-1850)

PIRIE, David B. (Ed.). The Romantic Period. London, Penguin Books 1994.

(The Penguin History of Literature, 5)

PRADO, Décio de Almeida. Leonor de Mendonça: Amor e morte em Gonçalves

Dias. In: . Teatro de Anchieta a Alencar. São Paulo, Perspectiva 1993, 243-297. (Debates, 261)

Ricardo, Cassiano. Gonçalves Dias e o indianismo. In: COUTINHO,

Afrânio (Dir.). A literatura no Brasil. v. 3. 3. ed. rev. e aum. Rio de Janeiro:

J. Olympio; Niterói, EDUFF 1986, 70-138.

ROMERO, Sílvio. História da literatura brasileira. v.3. 5. ed. Rio de Janeiro, José

Olympio 1953.

Ruthven, K. K. O mito. Tradução de Esther Eva Horivitz de Beermann.

São Paulo, Ed. Perspectiva 1997. (Debates, 270).

SCHILLER, Friedrich. Werke. 2 vol. München, Droemersche Verlagsanstalt 1954.

Os deuses da Grécia. In: MACHADO DE Assis. Poesias completas. Tradução

Machado de Assis. Rio de Janeiro, W. M. Jackson 1957, 228-233.

Guilherme Tell. Tradução e prefácio de Sílvio Meira. Rio de Janeiro,

Serviço Nacional de Teatro 1974. 
Maria Stuart. Trad. Manuel Bandeira. São Paulo, Abril Cultural 1977. (Teatro Vivo). A noiva de Messina. In: DIAs, Antônio Gonçalves. Teatro completo. Tradução Gonçalves Dias. Rio de Janeiro, Serviço Nacional de Teatro 1979, 365-467. (Coleção Clássicos do Teatro Brasileiro, 2)

. Os bandoleiros. Trad., org., prefácio, comentários e notas de Marcelo Backes. Edição comentada. Porto Alegre, L\&PM 2001. - A noiva de Messina on Os irmãos inimigos. Tradução de Gonçalves Dias. Notas de Manuel Bandeira. Organização de Márcio Suzuki e Samuel Titan Jr. São Paulo, Cosac \& Naify 2004. . Intriga e amor. Tradução e posfácio de Mario Luiz Frungillo. Curitiba, Editora da UFPR 2005. 